unanswered by the trial design. I have since undertaken a $\mathrm{PhD}$ applying qualitative methodology to explore trial phenomena, including process evaluation, case study and qualitative interviews. We applied the Diffusion of Innovations in Healthcare Settings ${ }^{\mathrm{a}}$ model to process data from the trial to explore high and low performing practices. This provided a rich picture of the intervention implementation process, as intended; however this data also prompted the need to revisit some of the assumptions upon which the trial was based. The trial assumed rapid testing would detect undiagnosed HIV however the exploration of patient data revealed this was not always the case. For example, already knowing their status, one patient used the rapid test to manage a number of factors related to their identity and personal circumstances, demonstrating the way testing and treatment creates meaning for patients. It also echoes what Annemarie Mol suggests in the Logic of Care, that we pay attention not only to what technologies are supposed to do, but what they happen to do. ${ }^{\mathrm{b}}$ This example, among other unexpected findings, highlights the need for a greater theorisation of the data and the unravelling of trial assumptions. We explore the experience of conducting qualitative analysis alongside a cluster randomised controlled trial related to a stigmatised illness and discuss the challenges and insights gained in the process.

${ }^{a} G$ reenhalgh $T$, Robert $G$, McFarlane $F$, et al. Diffusion of innovations in service organizations: systematic review and recommendations. Milbank Quarterly 2004;82: 581-629.

${ }^{\mathrm{b}} \mathrm{Mol}$ A. The logic of care: health and the problem of patient choice. London, United Kingdom: Routledge, 2008.

\section{PP BEYOND EFFECTIVENESS: CONDUCTING QUALITATIVE RESEARCH ALONGSIDE A CLUSTER RANDOMISED CONTROLLED TRIAL OF HIV TESTING IN GENERAL PRACTICE}

H McMullen, ${ }^{1 *} \mathrm{C}$ Griffiths, ${ }^{1} \mathrm{~T}$ Greenhalgh ${ }^{2} .{ }^{1}$ Queen Mary University of London, Department of Primary Care and Public Health, UK; ${ }^{2}$ Nuffield Department of Primary Care Health Sciences, University of Oxford, UK

*Presenting author.

\subsection{6/bmjopen-2015-UCLSymposiumAbstracts. 19}

I worked as a trial manager of a cluster randomized controlled trial of rapid HIV testing in primary care settings over a 2.5 year period. This left me with a number of questions that were 